\title{
POSTPANOPTISMO: LAS NUEVAS TECNOLOGÍAS DE VIGILANCIA EN LAS SOCIEDADES DE CONTROL
}

\author{
Postpanoptism: the new technologies of surveillance in the control societies \\ Alejandro Recio Sastre \\ Universidad de Valladolid, Valladolid, España \\ alejandrorecio13@gmail.com
}

\section{Resumen}

Las nuevas tecnologías están siendo aplicadas sistemáticamente en el desarrollo de las técnicas de control social, provocando que la vigilancia panoptista quede obsoleta, por tanto, solo cabría hablar de postpanoptismo. El postpanoptismo emerge en las sociedades de control superando el contexto de las sociedades disciplinarias. En la actualidad, el postpanoptismo opera en situaciones de excepcionalidad como instrumento de exclusión al margen de la legalidad constituida; también, la vigilancia en el espacio económico explota el dominio sobre los flujos de consumo, más allá de las técnicas disciplinarias que actúan en el ámbito productivo. La exposición de los cuerpos, deseos y hábitos de los individuos introduce una problemática ético-política sobre los mecanismos postpanoptistas.

Palabras clave: panóptico, postpanoptismo, banóptico, sinóptico, sociedades de control.

\begin{abstract}
The new technologies are systematically applied in the development of social control techniques, they are bringing obsolescence on the panoptic surveillance, there upon we could talk only about postpanoptism. The postpanoptism raises in the control societies overcoming the disciplinary societies context. Today the postpanoptism operates in the exceptionality moments like exclusion tool apart out the constituted legality. Also, the surveillance works in the economy space domain above flows of consumers, beyond disciplinary techniques that act in productive environment. The expose of the individuals' bodies, desires and habits introduces ethic-political problematic about postpanoptics mechanisms.
\end{abstract}

Keywords: panopticon, postpanoptism, banopticon, sinopticon, control societies.

Fecha de Recepción: 30/05/2018 - Fecha de Aceptación: 30/09/2018 


\section{Transición del panóptico al postpanóptico}

Un edificio circular, con una torre en el centro del plano arquitectónico, en torno a ella, se disponen unas celdas instaladas en el perímetro de la circunferencia (Bentham 43). Esta descripción corresponde al panóptico, un edificio creado por los hermanos Bentham, Samuel y Jeremy, cimiento sobre el que uno de ellos, el insigne filósofo utilitarista Jeremy Bentham, fundó su principio de inspección. Sobre la cartografía del panóptico se proyecta un plan de dominación basado en la vigilancia. La población hacinada en los márgenes del edificio es expuesta a una única mirada, la retícula de esta mirada es la torre de inspección, desde la que un solo hombre controla a una gran cantidad de individuos. Para Bentham, "cuanto más constante sea la vigilancia de los vigilantes sobre las personas confinadas, más felizmente se habrá logrado el objetivo de la institución" (40). La arquitectura panóptica cumple la finalidad de controlar a una población más o menos amplia sin incurrir en gran cantidad de gastos para ello.

En Vigilar y castigar Foucault le dedica no pocas referencias y comentarios al panóptico de Bentham, es en el capítulo siete, consagrado al edificio de inspección benthamita, donde el pensador francés dice que el jurisconsulto británico puso en práctica un poder inverificable, pues el vigilante ha de estar oculto con respecto al vigilado (2012 233). “El Panóptico es una máquina maravillosa que, a partir de deseos de lo más diferentes, fabrica efectos de poder homogéneos" (234). Foucault concibe al panóptico como un edificio transparente en el que toda la sociedad es invitada a evaluar las prácticas del poder; el panoptismo aumenta el poder, su sistema de presión sobre los cuerpos no se fundamenta en un dominio que asesta muerte sino en un ordenamiento que procura un incremento de las fuerzas productivas mediante la disciplina. La diferencia esencial entre el espacio de la peste y el espacio panóptico reside en que el segundo multiplica la potencia productiva de los cuerpos, volviendo económicamente útil el confinamiento de individuos. El sistema de vigilancia propuesto por Bentham analiza el cuerpo social y la subordinación de los cuerpos desde un punto de vista económico (240, 241).

El panóptico era presentado como la idea arquitectónica que desataría “el nudo gordiano de la ley de pobres" (Bentham 35), lo que implicaba transformar a una sociedad rural, acostumbrada al amparo parroquial y comunitario, en una sociedad industrial productiva. El objetivo último de Bentham no solo consistía en emplear e instruir indigentes, sino en crear las condiciones óptimas para fomentar el trabajo y el rendimiento productivo de la población (Polanyi 159,160). Se puede decir que el propósito biopolítico del sistema panoptista de vigilancia era modificar toda una estructura social cimentada sobre las garantías y certidumbres 
procuradas por las leyes de pobres en el seno de una población de raigambre campesina, anclada en instituciones tradicionales poco incentivadoras. El propio Foucault encuentra que en las sociedades liberales donde se gestó el panóptico el mercado requería de una gran masa de trabajadores lo suficientemente calificados para generar rendimientos económicos pero desprovistos de medios políticos de presión (Foucault 2007 85). El panoptismo resolvía esta ecuación con la maximización de la eficiencia productiva y la minimización de la resistencia política, de modo que implantaba un sistema de control sobre el sector más amplio de la población: los trabajadores. Este instrumento de vigilancia era propenso al estilo liberal de gobernar, en cuanto gobierno que vigila y que solo interviene allí cuando hay algún elemento que obstaculiza la dinámica de los mecanismos económicos (2007 89).

La mutación del panoptismo como tecnología anatomopolítica comenzó a gestarse con el tránsito de las sociedades disciplinarias a las sociedades de control. Maurizio Lazzarato afirma que el poder de las sociedades de control es puesto en práctica a través de las "tecnologías de acción a distancia de la imagen, del sonido y de los datos, que funcionan como máquinas de modular" (2006 92). Estas máquinas operan mediante ondas radiomagnéticas $y$ bits cristalizados $y$ modulados con el fin de generar conjuntos de imágenes, sonidos y datos. Para Lazaratto, el área del cuerpo específica sobre la que actúan las sociedades de control es el cerebro, ya no se instalan ritmos psicomotrices destinados a causar una mecánica sobre los movimientos de los cuerpos útiles para las actividades laborales. No se trata tanto de moldear los cuerpos, sino de moldear los cerebros; por ello, son instaurados unos hábitos aplicando técnicas de control noo-políticas, es decir, captar la atención de las personas para designar sus preferencias y modular la dimensión espiritual de los individuos contenida en sus pensamientos (93). Pero la sociedad de control no anula los dispositivos disciplinarios, más bien, Lazzarato considera que los retoma e integra (106), así, los cuerpos también son moldeados gracias a la sutilidad de las disciplinas filtradas y disimuladas en las facilidades y posibilidades que brindan las tecnologías.

La obsolescencia del panóptico se produjo en paralelo al proceso de integración de las sociedades disciplinarias en los nuevos aparatos de control, lo que no trajo consigo la desaparición del panoptismo, sino su transformación. El sistema de vigilancia diseñado por Bentham e interpretado por Foucault amplía sus márgenes de captación al diluir las acotaciones espaciales a las que se restringía el panóptico. Sigue manteniendo en plena latencia la impersonalidad, invisibilidad e inmaterialidad del poder, características que hacen de la vigilancia una función eficiente, pero, a parte de estas características, se suman la deslocalización y descentralización de la vigilancia. Las Tecnologías de la Información y la 
Comunicación (TIC) aumentan el radio de dominación gracias a las posibilidades que prestan en materia de control social. La creación de dispositivos tecnológicos para uso individual, tal como los Iphones, ha servido para que la disponibilidad laboral de los trabajadores sea prácticamente perpetua, debido a que los empleados se ven forzados a mantenerse en comunicación con sus jefes fuera del horario laboral. Evitar ser contactado a menudo es implícitamente considerado una falta y una razón suficiente para sufrir una sanción por parte de la dirección empresarial (Bauman y Lyon 2013 68).

Kevin D. Haggerty afirma que el panóptico ha sido superado y rebasado por el uso de las tecnologías actuales en actividades de vigilancia -controles biométricos, observación satélite, nanotecnología, etc.- (2006 32). La irrupción de las nuevas tecnologías, por tanto, ha transformado la racionalidad gubernamental panoptista en las dinámicas de observación de la población (41). Para Haggerty

merece la pena darse cuenta de que la imagen más duradera y profética del lugar de las tecnologías de la información en la vigilancia contemporánea fue prevista por Orwell (1949), que escribió décadas antes que Foucault y en pleno florecimiento de la nueva visualización de las tecnologías $(200633)^{1}$.

El panoptismo, tal como lo formuló Foucault, ha sido completamente transformado, lo que no resta que su simiente permanezca en pleno estado de floración dentro de las sociedades de control. Si Foucault negaba que el panóptico fuera un mero elemento onírico producto del ingenio de Bentham (2012 237), el postpanóptico sí da juego para hablar de componentes oníricos en su puesta en marcha, pues las alternativas que ofrecen las nuevas tecnologías y su acelerada evolución hace imaginables las peores pesadillas orwellianas: tal como lo revela uno de los personajes de la novela 1984, el funcionario del "Gran Hermano" llamado O’Brien, quien preconiza la manipulación de los individuos como mejor método para subsumirlos voluntariamente a la vigilancia total. "Al hereje político le quitamos todo el mal y todas las ilusiones engañosas que lleva dentro; lo traemos a nuestro lado, no en apariencia, sino verdaderamente, en cuerpo y alma" (Orwell 311). Las palabras de O’Brien simbolizan el principal objetivo estratégico postpanoptista, hacer del dominio algo querido y deseado por quienes lo reciben. No basta con la resignación ante el hecho de ser dominado, pues también hay que hacer del dominio algo querido. La producción de subjetividad desplegada por los contenidos informacionales que recorren las TIC hace de la vigilancia algo

\footnotetext{
1 "it is worth noting that the most lasting and prescient image of the place information techonologies in contemporary surveillance was provided by Orwell (1949), who wrote decades before Foucault and the full flowering of new visualizing technologies".
} 
habitual, sin ni siquiera la necesidad de recurrir a medios de presión directa sobre los cuerpos.

\section{Entornos de excepcionalidad y exclusión: el banóptico}

Un momento de auge postpanoptista tuvo lugar tras el atentado del 11 de septiembre de 2001 en Estados Unidos. Una vez esta potencia mundial fue sacudida, su presidente George W. Bush aprobó las military orders, llevando a cabo lo que Agamben considera una clara suspensión del derecho (2007 26). Bush había autorizado la detención de aquellos extranjeros que presumiblemente pudieran poner en riesgo la seguridad de Estados Unidos, para ello promulgó unas medidas que cancelaban los estatutos jurídicos de todos los ciudadanos, "produciendo así un ser jurídicamente innombrable e inclasificable" (Agamben 2007 27). La detención de los terroristas talibanes y el proceso al que posteriormente fueron sometidos no son comparables, ni resultan homologables, a cualquier otro procedimiento jurídico legal; en ese momento estaban actuando medidas excepcionales.

El postpanoptismo se nutre de la excepcionalidad, solo puede germinar en un contexto de suspensión jurídica. A diferencia del panóptico conceptuado por Foucault como un instrumento de coerción, cuyas actividades se inscriben dentro de los límites del derecho, en el "subsuelo de las libertades formales y jurídicas" (2012 255), el postpanóptico necesita entornos extrajurídicos para ponerse en funcionamiento. Las herramientas coercitivas a las que recurre el postpanoptismo no se ensamblan con los métodos coercitivos contemplados por el derecho; aunque huelga matizar que el panoptismo también nació en un momento histórico donde estaban produciéndose importantes cambios en la legislación, fue la lucidez de Bentham y la incorporación de una jurisdicción liberal las que pasaron de un contexto histórico tan excepcional como era el declive del Antiguo Régimen a una normalización de los nuevos espacios de disciplina.

Desde el año 2001, los escenarios de terrorismo se han extendido por prácticamente todo el mundo, con especial incidencia en oriente medio y en otros países del entorno islámico, así como también en Europa. Igual que en Estados Unidos en 2001, la incertidumbre generada en la población por los atentados terroristas dio pie a que los países europeos articularan políticas del miedo, sustentadas en la excepcionalidad. Tal y como comenta Castells al respecto, el terrorismo del fundamentalismo islámico ha generalizado el miedo y ha traído consigo que los ciudadanos admitan "que los vigilen y los controlen electrónicamente, que los cacheen en sus viajes, que los detengan preventivamente, que militaricen su espacio público" (Castells 2017 29). Las medidas preventivas son 
percibidas por la población como una serie de seguridades desplegadas en contra de los posibles terroristas, mientras tanto, de manera paulatina, "lo que son excepciones por motivos de seguridad se va convirtiendo en la regla que rige nuestras vidas" (2017 30).

El uso institucional de las nuevas tecnologías para crear sistemas de control social nos remonta a un asunto biopolítico en cuanto gobierno de las poblaciones. El control de la sociedad en la Globalización pone de relieve la cuestión de los flujos migratorios, Didier Bigo ha tratado este tema en "Security, exception, ban and surveillance" ("Seguridad, excepción, exclusión y vigilancia"). Al comienzo de su trabajo, Bigo afirma que "los estudios críticos de seguridad y los estudios de vigilancia tienen mucho en común”2 (2006 46). Los dispositivos de vigilancia y las medidas de excepción declaradas en momentos de extrema agitación han sido incrementados a partir del 11-S, de modo que las medidas de seguridad y los consecuentes dispositivos de vigilancia implementados se han ido multiplicando en diferentes facetas de la vida pública. Sin embargo, toda esta batería de medidas no siempre ha ido acompañada de declaraciones oficiales y formales del estado de excepción, ya que los gobiernos se han limitado a implementar estas medidas de una forma regular y habitual (2006 48). El afloramiento de la inseguridad afectó a la manera de concebir a ciertos sectores de la población migrante, lo que trajo consigo técnicas de exclusión sistemáticas:

La vigilancia global por coordinación de los diferentes servicios internos y por los diferentes nodos de compenetración en el nivel occidental es vista como un 'imperativo' que no puede ser retrasado por cualquier consideración de privacidad. Todos los políticos, también a favor de la guerra o por un enfoque más judicial, concuerdan con esta visión; la vigilancia más centralizada y globalizada sobre la gente en movimiento es la clave del éxito contra todos los males generados por la libertad de movimiento de personas ${ }^{3}(200656)$.

Los dispositivos de vigilancia, en adherencia a los nuevos sistemas tecnológicos han contribuido a agilizar la aplicación de los mecanismos de control social, como es el caso de las fronteras receptoras de inmigrantes, por tanto, el control de las fronteras y de las poblaciones ha llevado, tal como lo entiende Bigo, a la elaboración de un sistema de vigilancia que escapa a las nociones panoptistas, ya que su función se centra en las medidas de exclusión y discriminación (2006 52). El

\footnotetext{
2 "Critical security studies and surveillance studies have a lot in common".

3 "Global surveillance by coordination of the different services inside and by the different nodes of coordination at the Western level is seen as an 'imperative' which cannot be delayed by any consideration of privacy. Every politician, either in favour of the war or for a more judicial approach, agrees on this view; more centralized and globalized intelligence about the people on the move is the key to success against all the evils generated by freedom of movement of persons".
} 
dispositivo al que se refiere Bigo es el banopticon ${ }^{4}$-banóptico si preferimos castellanizar el término-. El banóptico constituye una modalidad postpanóptica que responde a un problema de especial repercusión política en las sociedades de control, tal como lo es el flujo migratorio. Según Lyon, "la función estratégica del diagrama del Banopticon consiste en determinar una minoría como 'excluida'" (Bauman y Lyon 2013 70), a lo que Bauman añade que en el banóptico "los instrumentos de vigilancia se dedican a 'mantener lejos', en vez de 'mantener dentro', como hacía el panóptico, y que se nutre y crece con el imparable crecimiento de las preocupaciones securitarias" (2013 70).

El sesgo que el postpanoptismo adquiere en lo relativo a la exclusión se localiza en los espacios de excepcionalidad, que, como bien destaca Agamben, encuentran su máxima expresión en los campos de concentración. Un campo de concentración "es una porción de territorio que se sitúa fuera del orden jurídico normal, pero que no por eso es simplemente un espacio exterior" (1998 216). En la contemporaneidad, -siguiendo uno de los ejemplos que proporciona Agambenlas zones d'attente de los aeropuertos internacionales de Francia siguen la lógica de los campos de concentración al retener a todos aquellos extranjeros que reclaman ser reconocidos como refugiados (1998 222). La matriz disruptiva del campo de concentración es la "que tenemos que aprender a reconocer a través de todas sus metamorfosis, tanto en las zones d'attente de nuestros aeropuertos como en ciertas periferias de nuestras ciudades" (1998 223, 224). El banóptico es una tecnología de exclusión que simboliza, de una manera muy completa, la lógica operativa concentracionaria.

\section{Estrategias de poder de los dispositivos postpanoptistas: citycams, sinóptico y vigilancia digital.}

Los dispositivos tecnológicos actuales se han instalado también en el ámbito del ocio y del consumo; el juego y las relaciones personales han sido agilizados, intervenidos, simplificados y rentabilizados gracias al uso de estas tecnologías. En el capitalismo de nuestros días, los dispositivos ocupan todas las facetas de la vida humana y, tal como comenta Agamben, profundizan la escisión entre la ontología y la acción, volviendo a los sujetos cada vez más lejanos del medio en el que viven, en la medida en que predomina la economía de los dispositivos sobre la ontología

\footnotetext{
${ }^{4}$ El banópticon es un juego de palabras entre "ban" y "óptico". Normalmente "ban" se traduce del inglés al español como "prohibir" o "prohibición", pero en el caso más específico en que lo emplea Bigo el término se traduce como "suspender", "rechazar" o "poner fuera"; estos conceptos se hallan en clara sintonía con la cuestión del banopticon como un instrumento que establece unos borders excluyentes y de segregación en los flujos poblacionales.
} 
de los sujetos (2015 26). Los dispositivos contemporáneos impregnan prácticamente todos los aspectos y gestos de la vida en las sociedades actuales (23 y 33); el postpanoptismo, que integra y articula estos dispositivos, adquiere un amplio nivel de influencia y penetración en las relaciones humanas, de ahí que la extracción de beneficios económicos desde los cuerpos y deseos captados sea el factor predominante en los mecanismos reticulares de gobernanza postpanoptista.

También conviene dar cuenta de cómo la esfera laboral se ha visto administrada según las directrices procedimentales de los dispositivos postpanópticos. La velocidad a la que fluyen los datos en las sociedades mediatizadas por las TIC instaura una lógica nómada en las relaciones de producción del capitalismo actual. Siguiendo a Gilles Deleuze y a Félix Guattari, los estados tratan de regular la velocidad nomádica con que se mueven las poblaciones (1986 59), no obstante, la maquinaria de guerra de las sociedades nómadas es incorporada por los estados y transformada según los objetivos de la estatalidad, de modo que los principios de supervivencia que movían las tendencias nomádicas son asimilados por el sedentarismo estatal. Este proceso se intensifica en el capitalismo:

Los factores que hacen que la guerra de Estado sea una guerra total están estrechamente ligados al capitalismo: tiene que ver con la inversión constante en el equipamiento, la industria y la economía de guerra, y la inversión de capital variable en la población en sus aspectos físicos y mentales (tanto como guerrero y víctima de guerra $)^{5}(117,118)$.

El capitalismo actual impone la itinerancia del trabajo mediante la flexibilización laboral, que deslocaliza las actividades productivas; las empresas y los trabajadores actúan como nómadas que se desplazan allí donde obtienen mayores rendimientos para el capital. La optimización de la producción y el incremento del capital condicionan a los seres humanos por encima de sus lazos familiares, determinaciones culturales, afinidades sociales y contextos locales. Una de las tendencias del sistema de poder en el nuevo capitalismo consiste en lo que Richard Sennett caracteriza como la "concentración sin centralización". Esta característica del sistema de poder procede de una nueva manera de organizar el trabajo "que da a la gente de categoría inferior más control sobre sus propias actividades" (2000 56). Pero ese control requiere de mecanismos de interiorización de la vigilancia, una tecnología subjetiva que ha de ser instalada en las mentes de los trabajadores. La administración de las empresas y la organización del trabajo contribuyen a una

\footnotetext{
5 "The factors that make State war total war are closely connected to capitalism: it has to do with the investment of constant capital in equipment, industry and the war economy, and the investment of variable capital in the population in its physical and mental aspects (both as warmaker and victim of war)".
} 
distribución especializada de las tareas de vigilancia, en función de la concentración de poder de mando en la gestión de las distintas actividades productivas y comerciales de las empresas. La gobernanza empresarial del capitalismo globalizado determina una nueva forma de gubernamentalidad, como dice Lazzarato, la "relación capital/trabajo ha quedado deslocalizada (cambio de territorio) y flexibilizada (movilizada dentro del territorio nacional)" (2015 140). La valorización del capital a través de la gestión privada de los recursos y servicios que prestaba el Estado de Bienestar coincide con los medios de producción de subjetividad, la gestión del sector público sigue las directrices de administración de las empresas privadas, de tal modo que la gobernanza es concebida y aplicada según las técnicas del sector privado (Lazzarato 2015 178,179). En este sentido, los mecanismos de vigilancia utilizados por las empresas, especialmente las grandes corporaciones transnacionales, se extienden a los espacios de realización de la vida pública; uno de los más importantes es el espacio urbano.

Hille Koskela utiliza el término "citycam" para referirse a las ciudades videovigiladas y conectado a internet, asimismo, emplea el término "camhome" para ámbitos privados (2006 164). Todos los acontecimientos acaecidos en las citycams son subidos a la red, lo que permite una observación en tiempo real de la ciudad. En la "Cam-era" se subvierten las tradicionales relaciones entre el poder y el control: el control no se halla arraigado a la forma de un poder concéntrico, sino que se diluye en nodos de vigilancia.

Las webcams, ofrecen representaciones visuales del espacio público y privado, muestra que el poder opera de maneras complejas. Cualquiera puede observar pero no es necesariamente capaz de ejercer poder o control en el sentido de que fueran observadores 'oficiales'. Los 'observadores' se convierten en 'espectadores'. El poder tiene al menos dos formas que conciernen a la comprensión conceptual de la vigilancia: primero, el poder trabaja a través de moralidades y control social, como la parte del espacio público mostrado en las ciudades-cam; y segundo, resiste el funcionamiento del poder a través de la naturaleza de la autorización de las webcams en el espacio privado ${ }^{6}$ (176).

Koskela presenta una ingeniería de vigilancia en la que el control y el poder se filtran en un entramado de relaciones complejas. La frontera entre lo público y lo privado no se halla delimitada rígidamente, los espacios videovigilados no tienen nada que ver con la clásica lógica operativa panoptista: las ciudades no son espacios descritos y tratados por Foucault, la ciudad es un espacio de encuentro y

\footnotetext{
6 "Webcams, offering visual representations of both private and public space, show that power operates in complex ways. Anyone can observe but is not necessarily able to exercise power or control in the sense that the 'official' observers were. The 'overseers' turn into 'viewers'. Power has at least two forms which contest the conceptual understanding of surveillance: first, power works through moralities and social control, as the part on public space citycams showed; and second, resisting power works through the empowering nature of home webcams in private space".
} 
no exactamente de aislamiento, la espacialidad penitenciaria es homogénea, mientras que "una ciudad está llena de diversidad. Esta diversidad -de ambos espacios y prácticas sociales- hace imposible comparar el espacio urbano simple y directamente al Panóptico"7 (2002 297).

Rodrigo Castro Orellana, en relación con las ciudades videovigiladas, ve en la revolución tecnológica de los últimos tiempos y en el incesante avance del neoliberalismo los factores que engendran el postpanoptismo. La "ciudad resort" de la globalización existe para ser vista, para desterritorializar aquellos elementos locales que forman parte de las singularidades de las poblaciones. El capitalismo neoliberal introduce unos deseos en el público que corresponden a las élites globales, caracterizadas por su desarraigo con respecto a lo local. Los ricos de la globalización ya no son vistos como enemigos ideológicos, sino como prototipos a seguir. Los globales transitan las ciudades mientras gobiernan y vigilan el sedentarismo de los locales, que viven recluidos en territorios cada vez más hostiles, lo que transforma la disciplina por medio de nuevos dispositivos tecnológicos: videocámaras, radares, instrumentos de localización biométrica, etc. (Castro Orellana 178). La tecnología que mejor se complementa con los medios denotadamente coactivos de vigilancia es el sinóptico, que invierte la lógica panoptista, al procurar que una mayoría observe a una minoría. La captura panóptica es sustituida por una captura sinóptica, que produce subjetividad y mueve a las multitudes mediante el control de la avidez. El cuerpo del individuo deja de ser el objeto de la mirada para pasar a ser "la máquina de ver"; asimismo, la ciudad, "desde este prisma, no se caracterizaría prioritariamente por una arquitectura concebida para posibilitar la intromisión de las técnicas de vigilancia. Ella sería velocidad y exhibicionismo, existiría cada vez más y exclusivamente para ser vista" (176).

La televisión es el dispositivo sinóptico por excelencia, cumple funciones noo-políticas por medio de las que se imponen directrices en la vida de cada uno de los individuos de la población. La aceptación, convicción, afinidad y complicidad con los contenidos y signos televisivos se reproducen hasta integrarse en los hábitos y pensamientos de una abrumadora mayoría de sujetos. La televisión irradia imágenes y discursos a una multiplicidad, es un dispositivo gestionado por una minoría de individuos pero que se agencia subjetividades a través de una constante influencia sobre los cerebros, además, impone una relación lateral y no recíproca entre el comunicador y el comunicante, impide toda reciprocidad entre ellos, de tal forma que elabora un discurso monolingüista destinado a formar al "hombre medio" (Lazzarato 2006 152,154). La diferencia

\footnotetext{
7 "a city is full of diversity. This diversity -of both spaces and social practices- makes it impossible to compare urban space simply and directly to the Panopticon".
} 
básica entre la televisión y la cibernética es que la primera muestra imágenes reales mientras que la segunda sólo muestra posibilidades de lo real, es decir, se mueve en lo virtual (Sartori 36,37). La televisión modifica considerablemente la forma en que el homo sapiens entiende la realidad, ya que el discurso que ofrece la televisión se halla contenido fundamentalmente en las imágenes (40).

Convenimos con la crítica de Sartori al dispositivo televisivo en que la preponderancia de la imagen sobre la lógica discursiva contribuye al predominio de lo emocional sobre lo intelectual (119). De este modo, Sartori denomina "vídeoniño" a alguien que se deja llevar por los contenidos circunscritos a las imágenes prescindiendo de los contenidos intelectuales de las palabras. El autor entiende, conspicuamente, que en los contenidos televisivos "es el productor el que produce al consumidor" (143). La utilización de estrategias de marketing para controlar las audiencias según intereses estrictamente comerciales le otorga a la televisión un poder de manipulación de amplísima extensión social. El "vídeo-niño" se convierte en el individuo mayoritario, afirma Sartori que "el vídeo-niño ha perdido la capacidad de usar el lenguaje abstracto del homo sapiens, (...), para recaer en la imprecisión y en el 'primitivismo cognitivo' de la conversación ordinaria, del lenguaje común" (185).

Con la llegada de internet y su comercialización a escala global las técnicas de vigilancia vuelven a ocupar un papel importante en las políticas de manipulación y control de la sociedad y la opinión pública. Si el sinoptismo vierte contenidos que uniforman y empobrecen las mentes, internet permite, además, que este vertido de contenidos facilite la selección de los nichos de población más rentables económicamente y dóciles desde el punto de vista político, gracias a una observación continua de las preferencias de los usuarios en la red. Castells da cuenta de cómo las democracias occidentales se han visto afectadas por técnicas de marketing político. El primer partido político que utilizó las técnicas MLM (marketing multiversal), fue el Partido Republicano de EEUU (2009 286). Mathew Dowd, analista y estratega de G.W. Bush, creó el Voter Voult, un sistema de puntos que recoge datos procedentes de los internautas para determinar las probabilidades de voto de estos. La obtención de tales datos se obtuvo observando los comentarios, las suscripciones a revistas, los registros de preferencias de consumo, etc. (287), con el claro propósito de que el partido intensificara o rebajara ciertos discursos según qué territorios. Tras las campañas electorales $-\mathrm{y}$ también tras las campañas de marketing comercial- hay una trabajada recopilación de datos que elabora mensajes selectivos en función de las sensibilidades de los votantes -o con arreglo a las preferencias de los consumidores-, con el fin de obtener un rédito que no siempre va a favor del ciudadano. Todo ello requiere de un dispositivo de vigilancia capaz de clasificar a la población. 
La transparentación de los deseos, el acceso por parte de las instancias del poder a las preferencias de los usuarios de la red, hace de la transparencia un instrumento político que en cierto modo va más allá de la vigilancia en un sentido "clásico-disciplinario". En "la sociedad de la transparencia" surge lo que ByungChul Han llama el panóptico digital, que se diferencia del panóptico disciplinario en que exhibe a unos moradores que no se aíslan sino que entran voluntariamente en unas redes que les exponen ante los otros (Han 89). Los moradores del panóptico digital son clientes (93), su rol es el de un consumidor más que el de un productor. Según Han, "el globo entero se desarrolla en pos de formar un gran panóptico" (94), los individuos se exponen a la mirada panóptica voluntariamente, de tal modo que la vigilancia deja de ser una expresión de coacción contra la libertad. "El morador del panóptico digital es víctima y actor a la vez. Ahí está la dialéctica de la libertad que se hace patente como control" (95).

El alto nivel de transparencia que las nuevas tecnologías pueden llegar a producir en las relaciones humanas y en la interacción de los individuos con su medio social irrumpe en la vida de los ciudadanos, entre otras cosas, porque esta transparencia facilita el acceso de la vigilancia $\mathrm{y}$, de hecho, la vigilancia implementa mecanismos de control de calado y carácter político. En las conversaciones de Julian Assange con sus compañeros el activista y creador de Wikileaks manifiesta una preocupación por la escala que está alcanzando la vigilancia en relación con la cantidad de población: "nos encontramos en un momento en el que la población humana se está duplicando cada veinticinco años -pero la capacidad de vigilancia se está duplicando cada dieciocho meses" (Assange 51). Cabe suscribir, junto a las conclusiones que extrae Assange, que la vigilancia en gran escala es una amenaza para la libertad y para la democracia que a todos urge controlar.

\section{Conclusión}

El postpanoptismo es un fenómeno gubernamental y no únicamente una tecnología disciplinaria más; este fenómeno gubernamental no se encarna en la forma de un edificio o institución. En el postpanoptismo se conjugan formas de dominación de connotaciones variables que, más que resultar incompatibles entre sí, responden a mecanismos de control cada vez más amplios debido a las aportaciones de las nuevas tecnologías. Junto a la incrementación de las técnicas de poder implementadas por estas tecnologías, el neoliberalismo trajo consigo la extensión de la vigilancia a actividades de consumo y ocio, además de la actualización de la disciplina productiva capitalista. En un contexto global en el que supuestamente prima la libre circulación del trabajo y de la riqueza, las 
prácticas de exclusión resultarían contradictorias para la opinión pública, por este motivo la modalidad postpanóptica excluyente (el banóptico), requiere especialmente de situaciones de excepcionalidad, pero también de aparatos de difusión que acostumbren y “docilicen” a la población. La vigilancia postpanóptica se ha vuelto más próxima al espionaje que a la vigilancia disciplinaria, que siempre opera sobre individuos conscientes de estar situados en el lugar del vigilado. Los medios sinópticos facilitan la captación, la segregación y la aplicación de medidas económicas agresivas, estas prácticas de control se hacen tolerables mediante la producción de subjetividad. La construcción de unos usuarios susceptibles de ser captados y clasificados por medio de técnicas de marketing que funcionan tanto en el espacio democrático como en el mercantil permite el aislamiento selectivo de la población según intereses ajenos a la mayoría social.

\section{Bibliografía}

Agamben, Giorgio. Estado de excepción. Homo sacer, II, I. Buenos Aires: Adriana Hidalgo editora, 2005.

Agamben, Giorgio. Homo sacer. El poder soberano y la nuda vida I. Valencia: Pretextos, 1998.

Agamben, Giorgio. ¿Qué es un dispositivo? Seguido de El amigo y de La Iglesia y el Reino. Barcelona: Anagrama, 2015.

Assange, Julian. Criptopunks. Montevideo: Trilce, 2013.

Bauman, Z. y Lyon, D. Vigilancia líquida. Barcelona: Paidós, 2013.

Bentham, Jeremy. Panóptico. Alcalá (Madrid): Círculo de Bellas Artes, 2011.

Castells, Manuel. Comunicación y poder. Madrid: Alianza Editorial, 2009.

Castells, Manuel. Ruptura. La crisis de la democracia liberal. Madrid: Alianza Editorial, 2017.

Castro Orellana, Rodrigo. “La ciudad apestada. Neoliberalismo y postpanóptico”. Revista de ciencia política, 29/1 (2009), 165-183.

Deleuze, G. y Guattari, F. Nomadology: the war machine. USA: Semiotext(e), 1986.

Foucault, Michel. Nacimiento de la biopolítica. Buenos Aires: Fondo de Cultura Económica, 2007. 
Foucault, Michel. Vigilar y castigar. Madrid: Siglo Veintiuno Editores, 2012.

Han, Byung-Chul. La sociedad de la transparencia. Barcelona: Herder, 2013.

Koskela, Hille. “Cam era' -the contemporary urban Panopticon”. Surveillance $\mathcal{E}$ society 1(3), 2002: 292-313.

Lazzarato, Maurizio. Por una política menor. Acontecimiento y política en las sociedades de control. Madrid: Traficantes de sueños, 2006.

Lazzarato, Maurizio. Gobernar a través de la deuda. Buenos Aires: Amorrortu, 2015.

Lyon, David (ed.). Theorizing of surveillance. The panopticon and beyond. USA and Canada: William Publishing, 2006.

- Haggerty, Kevin D. "Tear down the walls: on demolishing the panopticon".

- Bigo, Didier. "Security, exception, ban and surveillance".

- Koskela, Hille. "The other side of surveillance: webcams, power and agency".

Orwell, George. 1984. Barcelona: Austral, 2011.

Polanyi, Karl. La gran transformación. México D.F: Fondo de Cultura Económica, 1992.

Sartori, Giovanni. Homo videns. Taurus, Madrid, 2012.

Sennet, Richard. La corrosión del carácter. Barcelona: Anagrama, 2000. 